\title{
¡A LAS URNAS, EN DEFENSA DE LA FE! LA MOVILIZACIÓN POLÍTICA CATÓLICA EN LA ESPAÑA DE COMIENZOS DEL SIGLO XX*
}

\section{Rosa Ana Gutiérrez Lloret}

El comienzo del siglo XX significó en muchos países europeos el triunfo de la «Nueva Política», un fenómeno que no podemos desligar de la democratización de los sistemas liberales, de la irrupción de las masas en la vida política y de una modernización que llevaba pareja la progresiva secularización del Estado y la conformación de una nueva sociedad, en la que la religión quedaba relegada al estricto plano espiritual ${ }^{1}$. Ante este contexto, vislumbrado como una amenaza a su influencia ideológica, social e institucional, la Iglesia responde impulsando la movilización social y política a través de diversas acciones que se articularon en el denominado movimiento católico y que, en la vertiente política, fructificaron en países como Italia, Francia, Bélgica o Alemania en potentes partidos católicos con notable proyección en la vida pública y una activa presencia político-electoral. España, si bien presentó notables diferencias respecto a los otros países europeos, no fue ajena a un proceso de respuesta o «defensa católica» que, frente a la modernización y secularización, se vertebró en diversos planos o vertientes, presentando también una dimensión política y un notable activismo propagandístico y organizativo².

* Este trabajo se inserta en el proyecto de investigación GV04B-542, que fue financiado por la Generalitat Valenciana.

1. ÁlvareZ TARDío, Manuel: «Política y secularización en la Europa contemporánea», Studia Histórica. Historia Contemporánea, no 16 (1998), pp.143-166.

2. Para el caso español, sigue siendo una referencia bibliográfica fundamental para la comprensión del movimiento católico español desde finales de siglo XIX hasta el franquismo, el libro de Montero García, Feliciano, El Movimiento Católico en España, Madrid, 1993. En el caso español el interés por la creación de un partido católico parece estar más relacionado con la clásica teoría de la sociología histórica que lo interpreta como 


\section{El origen de la «defensa católica»: El impulso de los Congresos Católicos}

Tras el compromiso que supuso el Concordato de 1851 al fin de la guerra carlista y la revolución liberal, la primera postura defensiva de la Iglesia frente a los avances secularizadores del liberalismo se situó en el marco de la lucha contra la libertad de cultos consagrada en la Constitución de 1869 y las medidas legisladoras de carácter laico de la revolución de 1868 y la Primera República ${ }^{3}$.

Con la restauración de la monarquía borbónica en España y la Constitución de 1876, se inauguró una nueva etapa en la que la Iglesia gozó de unos privilegios dentro de un marco limitado que facilitaron que sus relaciones con el Estado discurrieran por cauces más amigables, haciendo innecesaria la organización y desarrollo de un movimiento católico ${ }^{4}$. No obstante, en la última década del XIX, el anuncio de algunos proyectos legislativos del partido liberal que pretendían una progresiva, aunque matizada, incorporación de la herencia reformista y laica propia del liberalismo progresista y democrático del sexenio, los lentos pero perceptibles cambios sociales y culturales que implicaba la modernización, los avances del socialismo y del anarquismo, y el incremento de la propaganda laica o anticlerical inquietaban a los católicos y a las jerarquías eclesiásticas.

Fueron éstas, conscientes además de que la división de la opinión católica entre diversas opciones político-confesionales se traducía en una débil capacidad de oposición, las que, en la última década del siglo XIX, tomaron la iniciativa de organizar y movilizar a los católicos con la fórmula de

respuesta al desarrollo del anticlericalismo y los partidos de masas. La existencia, por otra parte, de un sólido partido conservador influirá decisivamente en que aquél no termine de consolidarse. Véase KALYVAS, S.N., «La formazione dei partiti confessionali in Europa», Rivista Italiana di Scienza Política, XXVI, n. ${ }^{\circ}$ (1996), pp. 317-363, esp. pp. 320-321.

3. La discusión sobre la libertad de cultos en el contexto de elaboración de la Constitución de 1869 generó polémica y el primer ejemplo de movilización católica. Véase Rico AMAT, Juan, La Unidad Católica: Biografía y discursos de los diputados católicos, que han tomado parte en los debates sobre la cuestión religiosa..., Madrid, R. Moreno, 1869 y Petición dirigida a las Cortes Constituyentes en defensa de la unidad católica de España, Imp. de «La Esperanza», Madrid, 1869. Casi treinta años después, los obispos, reunidos en la primera Asamblea episcopal española, celebrada en mayo de 1907, coincidían en la necesaria «reivindicación de los derechos usurpados a la Iglesia desde la revolución de 1868», en Archivio della Sacra Congregazione degli Affari Ecclesiatici Straordinari (Vaticano), Spagna, 1906-1907, Pos. 1027, fasc. 409.

4. Callahan, Willian J., «Los privilegios de la Iglesia bajo la Restauración, 1875-1923», en BOYD, Carolyn P. (ed.), Religión y política en la España contemporánea, Madrid, 2007, pp. 17-32. 
los denominados Congresos Católicos. Impulsados por el cardenal Sancha, obispo de Ávila, pretendían exportar a España el modelo italiano de L'Opera dei Congressi que había potenciado León XIII. Estos Congresos, que tendrán lugar en diversas ciudades españolas entre 1889 y 1902, sembraron la semilla del movimiento católico al crear plataformas para la acción de los católicos en diversas esferas de la actividad pública y social ${ }^{5}$, pero también pusieron en evidencia las dificultades existentes para la coordinación política por la profunda y antigua división entre las diversas tendencias políticas confesionales (carlistas, integristas, y neutros, posibilistas o mestizos) y el desacuerdo con la jerarquía eclesiástica, a su vez profundamente dividida ${ }^{6}$.

Los primeros Congresos constataron una cierta apatía e importantes divergencias entre los católicos, problemas que se expresaron de forma crítica en 1894, en el Congreso de Tarragona y dos años más tarde en el informe remitido por la Nunciatura de Madrid al Vaticano ${ }^{7}$, que reflejaba un panorama tan desalentador que explica la paralización de los Congresos Católicos en los años siguientes. Fue en 1899, con un catolicismo marcado también por el regeneracionismo posterior al Desastre y deseoso de recuperar protagonismo social y político, cuando se da un nuevo impulso a la movilización católica con la convocatoria del Congreso de Burgos ${ }^{8}$.

Este Congreso fue decisivo como punto de arranque de esa movilización. En él, además del reconocimiento expreso, como objetivo, de la «viril defensa de los derechos imprescriptibles de la Iglesia» y de procurar la unión para acabar con «las tristísimos divisiones existentes entre los católicos de España», se elaboraron y aprobaron las primeras normas para la acción política y social de los católicos, que serán la base reguladora del activismo católico hasta la encuesta promovida por el Nuncio Vico en 1908 y las Normas del cardenal Aguirre en 1910:

5. Carta Pastoral del Emmo. y Revmo. Señor Cardenal Martín Herrera, Arzobispo de Santiago, sobre el Congreso Católico de Compostela, Santiago, 1902

6. Una radiografía clara del origen y enfrentamiento entre las diversas tendencias y partidos que reclamaban para sí la defensa programática del credo católico en la esfera política, en SANTANDER Ruíz-GimÉnez, Federico, Los católicos y la política, Valladolid, 1913, pp. 7-25.

7. Rapporto della Nunziature Apostolica in Madrid sulla Azione Cattolica nell Ordine Pubblico in Spagna. Archivio della Sacra Congregazione degli Affari Ecclesiatici Straordinari, Spagna, 1896, fasc. 279. Existe una transcripción traducida en CÁrCEl OrTí, Vicente, León XIII y los católicos españoles. Informes vaticanos sobre la Iglesia en España, Pamplona, 1988, pp. 893-944.

8. Un análisis pormenorizado del Congreso de Burgos en relación con la coyuntura del 98 en Montero GarCía, Feliciano, «El catolicismo español finisecular y la crisis del 98», Studia Histórica. Historia Contemporánea, no 15 (1997), pp. 221-237 y 227-237. 
«Los tiempos han cambiado completamente, y hoy es fuerza que los católicos se agrupen, se organicen y trabajen aunadamente y con perseverancia en la reivindicación de sus derechos, usando para ello de todos los que al ciudadano se reconocen en la sociedades modernas. El espíritu de asociación, que caracteriza a este siglo, ha sido la palanca de Arquímedes con que se han removido tantos obstáculos y se han hecho obras verdaderamente extraordinarias...» ${ }^{9}$.

Los deseos de unidad católica del Congreso tomaron forma en las «Bases y programa para la unión político-electoral». En ellas se reconocía como deseable la opción política posibilista de participar en las elecciones bajo la fórmula de la unión de los católicos, dirigida por los obispos e independiente de los partidos políticos existentes, con el fin de evitar la división de fuerzas. Se proclamaban las reivindicaciones de la Iglesia en un programa adjunto, en el que se anunciaban ya las futuras líneas de lucha, propaganda y activismo católico, reclamando y defendiendo como legítimos los instrumentos propios del sistema liberal:

«Medios para conseguir este fin (...) serán los que la legalidad existente pone en nuestras manos, especialmente las elecciones para todos los mandatos y cargos públicos, la prensa periódica, el derecho de asociación y el tomar parte activa en todos los actos, oficios y empleos de la vida pública, bajo la dirección del Episcopado» ${ }^{10}$.

De este Congreso nacieron, pues, las nuevas perspectivas para la acción católica: un desarrollo sin precedentes de la prensa católica como instrumento de propaganda, la actuación concreta en el ámbito laboral y sindical, y un nuevo asociacionismo de base confesional que cubría múltiples facetas de la vida social y en el que los católicos seglares iban a tener un gran protagonismo ${ }^{11}$. En este contexto debemos situar importantes iniciativas asociativas como la constitución en 1900 de la Junta Central de Acción Católica en Madrid, o la creación en 1903 del Centro de Defensa Social de Barcelona que, como las Ligas Católicas, constituye otra fórmula para encuadrar políticamente a los católicos y que acabará exportándose a otras ciudades como Mallorca ${ }^{12}$ y Madrid, donde desplegó una actividad muy diversa en la propaganda y la acción

9. Crónica del $5^{\circ}$ Congreso Católico español, celebrado en Burgos el año 1899, Burgos, Imp. y Est. De Polo, 1899. Las citas textuales corresponden a la carta pastoral de Aguirre, Arzobispo de Burgos, sobre los Congresos Católicos, de fecha 9 de febrero de 1899, que encabeza la publicación de las actas del Congreso, pp. 27-41, esp. p. 29 y 36-37.

10. Ibid., p. 639 (Base Quinta).

11. Montero, Feliciano, El Movimiento Católico ..., p. 22

12. Fullana Puigserver, Pere, El moviment catòlic a Mallorca, 1994, p. 575 y ss. 
social y política ${ }^{13}$. Unos años más tarde, en la línea del catolicismo social, el P. Gabriel Palau fundaba en Barcelona otra activa asociación: la Acción Social Popular ${ }^{14}$.

También la propaganda con el fomento de la llamada «Buena Prensa» fue objeto preferente de la movilización católica, bien bajo la tutela de las jerarquías católicas, bien desde las asociaciones de base ${ }^{15}$. En este campo destacan las numerosas publicaciones de ámbito local y aquellas otras que, como El Universo, La Lectura Dominical, La Paz Social, El Correo de Andalucía, La Revista Popular, contaron con una amplia difusión al ser publicadas en las grandes capitales del país ${ }^{16}$. El interés por impulsar la «Buena Prensa» en el primer decenio del XX se refleja también en numerosos folletos u obras propagandísticas y en la incesante labor que en este campo realizaron sus principales apologistas, como el sacerdote Polo Benito y el obispo Antolín López Peláez ${ }^{17}$. Así pues, podemos afirmar que, a comienzos de siglo, se podían observar notables avances de la movilización católica en iniciativas concretas como el asociacionismo o la propaganda, pero el balance en el plano político electoral no era tan positivo. La tan ansiada unión política de los católicos y la defensa en la lucha electoral frente al laicismo chocaban con muchos problemas, bien porque su programa estaba cautivo de las opciones políticas que se proclamaban confesionales, bien por las reticencias existentes en una parte de la jerarquía católica española, a pesar de que se trataba de una iniciativa auspiciada por el Vaticano. Sin embargo, y aunque, como ha señalado Cueva Merino, el movimiento católico se desarrolló en buena parte fuera de

13. «Cuyo objeto será la defensa y fomento de los intereses morales y sociales... fomentar la buena prensa y la enseñanza entre las distintas clases sociales, oponiéndose por todos los medios que la ley autoriza a aquello que pueda ser contrario, a juicio de esta Sociedad, a esos mismos intereses...». Estatutos del Centro de Defensa Social, Madrid, Tipografía Española, 1906.

14. Sobre la organización y la labor desarrollada por la asociación, véase La «Acción Social Popular». Su finalidad. Sus servicios. Sus ventajas. Su desarrollo, Barcelona, s.a. (i1914?)

15. La insistencia en la propaganda y el contar con instrumentos de difusión como los periódicos católicos centraron también los debates del Congreso de Burgos. Véase Crónica..., pp. 379-414.

16. Sólo El Universo, como portavoz de la Junta Central de Acción Católica, tendrá una difusión más amplia, pero los católicos no contaron con un periódico de vocación nacional hasta la aparición de El Debate en octubre de 1910.

17. Polo Benito, José, Del periodismo católico, Plasencia, Imp. de Manuel Ramos, s.a.; LóPEZ PelÁEZ, Antolín, La importancia de la prensa, Barcelona, Gustavo Gili Ed., 1907. Un análisis de la «Buena Prensa», en SÁNCHEZ SÁNCHEZ, Isidro, «El Pan de los fuertes: La Buena prensa en España», en Clericalismo y asociacionismo católico en la España de la Restauración a la Transición: Un siglo entre el palio y el consiliario, 2005, pp. 51-105. 
los cauces políticos del sistema de la Restauración ${ }^{18}$, siempre tuvo presente una dimensión política y electoral. De hecho, además de los llamamientos o manifiestos políticos en sentido estricto, las iniciativas asociativas y propagandísticas y las grandes campañas de movilización de la opinión católica «en defensa de la Fe» siempre tuvieron a la vista objetivos electorales y políticos que, en algún caso, se llegaron a expresar de forma directa en los estatutos y memorias de asociaciones como la Acción Social Popular ${ }^{19}$, o el Centro de Defensa Social de Madrid ${ }^{20}$, y que se recogían en muchos ensayos propagandísticos que se publicaron en esos años. Claramente ilustrativa al respecto es la obra de López Peláez sobre la prensa católica y su finalidad, cuando aborda la relación entre prensa, política y elecciones:

«No: sin tener lectores no esperemos electores: si aspiramos a una buena elección, propaguemos las buenas lecturas; antes de luchar en los comicios, luchemos en la prensa».

«Aún dado que llevásemos a las Cortes y a los municipios numerosa representación del elemento católico, su fuerza sería poco eficaz si no actuaba sobre la opinión por medio de la palanca de la prensa (...) La voz de nuestros oradores se estrellaría contra las paredes de las Cámaras y quedaría ahogada en su recinto, si la prensa no la sacara de allí para llevarla hasta los últimos confines de la patria (...) dar a nuestra prensa mayor circulación, de suerte que en todas partes haga oír su voz educadora (...) y reconquiste la conciencia nacional disipando los recelos y prevenciones con que miran muchos la acción política y social de los católicos». ${ }^{21}$

De esta forma, el catolicismo político español iniciaba su compleja andadura contemplando desde sus inicios una doble y contradictoria faceta entre unos contenidos ideológicos reaccionarios y contrarios a la modernización, y unas

18. Cueva Merino, Julio de la, «Católicos en la calle: La movilización de los católicos españoles, 1899-1923», Historia y política, no 3 (2000), pp. 55-79, esp. p. 59. El autor cita la argumentación que, en este sentido, realiza Frances Lannon en un trabajo inédito.

19. «(La A.S.P.) no constituye un partido político, aunque sí forma y educa para cumplir todos los deberes sociales y civiles y propugna la necesidad de servirse, en la medida lícita, de los derechos de ciudadano» (Art. 2 c)

«La A.S.P. pretende principalmente a) educar la conciencia social, civil, moral y religiosa (Art. 3), en La «Acción Social Popular», op. cit, p. 12.

20. El C.D.S. comenzó a organizar en 1907 una sección electoral «con sujeción absoluta e incondicional a las Encíclicas y Pastorales (...) nos prepararemos, pues, para ir a las elecciones». Centro de Defensa Social. Memoria leída por el secretario P. P. de Alarcón, Madrid, Revista de Archivos, 1907, p. 15.

21. Ambos párrafos pertenecen a su ensayo La importancia de la prensa, op. cit. El primero al capítulo «La prensa gana elecciones», p. 151 y el segundo al titulado «Sin prensa no hay política», pp. 165-167. Opiniones similares se recogieron en la Crónica de la Segunda Asamblea Nacional de la Buena Prensa, celebrada en Zaragoza..., Tip. La Editorial, 1909, p. 151. 
formas organizativas, periódicos, tejido asociativo y propaganda, claramente modernas y beligerantes. Dicha contradicción se hacía más evidente en el escenario electoral en el contraste entre discurso que, ideológicamente, contenía un marcado poso antiliberal y una estrategia de movilización y participación activa del electorado católico muy alejada de la praxis electoral caciquil que le era propia al sistema político de la Restauración.

\section{Los inicios de la movilización electoral: Las Ligas católicas y la unión de los católicos (1903-1905)}

Con el cambio de siglo, los católicos contemplaron con temor la formación del nuevo gabinete liberal presidido por Sagasta ${ }^{22}$ y la pujanza del discurso anticlerical en estrecha conexión con el desarrollo de un nuevo republicanismo de corte radical en algunas ciudades ${ }^{23}$. En un creciente clima de incertidumbre, las líneas de actuación en el ámbito político y electoral esbozadas en el Congreso de Burgos comenzaron a fructificar con la constitución de las Ligas Católicas ${ }^{24}$, que nacían con una clara vocación hacia la acción política confesional. Así lo reconocía la Liga Católica de Pamplona, puesto que su finalidad era el defender «los intereses religiosos, principalmente en la elección de diputados católicos» ${ }^{25}$.

Las elecciones generales en 1903 fueron la oportunidad para que estas Ligas y, en general, los grupos católicos pudieran participar en la lucha electoral de manera más organizada y cohesionada, contando además con órganos de prensa y propaganda creados en varios puntos de la geografía peninsular gracias al impulso propagandístico que trajeron consigo los Congresos Católicos.

22. Su temor se materializa en el proyecto sobre el matrimonio civil y, en especial, en el R.D. del 19 de septiembre de 1901, considerado una amenaza directa a las órdenes religiosas como reflejan las pastorales de algunos obispos y los artículos de reconocidas revistas católicas. Véase, por ejemplo, el Boletín Eclesiástico del Arzobispado de Burgos, 13-5-1901, y Razón y Fe, I, Madrid, 1901, pp. 327-333 y 437-454.

23. El estreno de la obra Electra del escritor Pérez Galdós en febrero de 1901 generó un ambiente de agitación anticlerical, REvUELTA GONZALEZ, Manuel, La Compañía de Jesús en la España Contemporánea, Madrid, 1991, II, p. 746 y ss.

24. Las Ligas de Valencia y Sevilla fueron las primeras y las que tendrían más larga duración, pero también se organizarán en Navarra, Zaragoza, Valladolid y otras ciudades españolas. Los estudios más detenidos corresponden a esas dos primeras Ligas: REIG, Ramir, Blasquistas y Clericales. La lucha por la ciudad en la Valencia de 1900. Valencia,1986 y Ruiz SÁnCHEZ, Jose L., Política e Iglesia durante la Restauración. La Liga Católica de Sevilla (1901-1923), 1994. Sobre las de Navarra, RoBLES MuÑOz, Cristóbal, «Católicos y participación política en Navarra (1902-1905)», en I Congreso General de Historia de Navarra, Príncipe de Viana, 1986, Anejo 10, pp. 405-414.

25. Archivio Segreto Vaticano (en lo sucesivo ASV), Nunziatura di Madrid, leg. 654, fasc.2, ff. $10-14$. 
Algunas Ligas, como las de Sevilla y Valencia, contaban con el inestimable apoyo de periódicos que se convertirán en portavoces de la organización y la propaganda de los católicos, como El Correo de Andalucía y La Voz de Valencia ${ }^{26}$. En otras ciudades, donde no se formaron Ligas o éstas carecen de órganos de prensa, la propaganda católica se canaliza principalmente a través de publicaciones, hojas parroquiales, folletos y los Boletines de los Obispados.

En primer lugar, esta propaganda católica se dirigía a estimular la participación política de los católicos, como primer paso para la articulación de un espacio electoral propio. A esta finalidad, responde el folleto ;Los católicos a las elecciones! que, publicado en 1903, les daba a las contiendas electorales el carácter de cruzada: «¡Hay que descender a la lucha por la Religión! ¡Hay que acercarse a las urnas por Jesucristo! ¡Hay que ir a los Comicios por la Iglesia! ¡Hay que votar, en una palabra, solamente a los católicos!» ${ }^{27}$. La segunda dimensión de la propaganda era el llamamiento a la unión de los católicos, que se hacía ahora más necesario al hacerse pública la carta de León XIII que, fechada el 22 de abril de 1903, instaba a la unidad de acción católica en España bajo la dirección del cardenal Sancha ${ }^{28}$. Con este respaldo, éste convocó una reunión con varios obispos para iniciar los trabajos de unidad ${ }^{29}$, aunque éstos no darían los frutos esperados ni en 1903, ni en 1905.

La Liga de Sevilla aprovechó las elecciones provinciales, previas a las legislativas de 1903, para organizar un centro electoral en la sede de El Correo, con comisiones formadas por «respetables y conocidas personalidades» y no por «muñidores y resucitamuertos» que, distribuidas por los distritos, se encargarían de coordinar la lucha electoral ${ }^{30}$. Aunque, finalmente, a consecuencia del pacto entre los partidos dinásticos, se optó por el retraimiento electoral, la campaña fue aprovechada como experiencia de cara a las generales y para intensificar su propaganda política, que se centró básicamente en la reproducción y comentario de documentos pontificios.

26. Ruiz SÁNCHEZ, José L., «Los católicos sevillanos en las crisis de la Restauración», Revista de Historia Contemporánea, $\mathrm{n}^{\circ} 7$ (1996), pp. 103-128, esp. pp.108-109 y COMES IGLESIAS, Vicente, «Movilización católica en una capital republicana, 1901-1910», en Estudios sobre la derecha española contemporánea, Madrid, 1993, pp. 121-131, esp. p. 125.

27. Gran Apostolado de las Señoras. ¡Los católicos a las elecciones!, Madrid, La Semana Católica 1903, p. 5, 10 y 24.

28. VilladA, Pablo, «La unión de los católicos españoles», Razón y Fe, VI, Madrid, 1903, pp. 277-285.

29. ASV, Segretaria di Stato, Anno 1903, Rubrica. 249, fasc.1, ff. 79-89.

30. Ruiz Sánchez, José L., Política e Iglesia durante la Restauración...., p. 132. Los textos entrecomillados aparecen así en la obra citada. 
En Valencia, la Liga Católica concurrió a las elecciones, utilizando como vehículo de propaganda su periódico La Voz de Valencia, que daba difusión a las recomendaciones electorales recogidas en publicaciones eclesiásticas y ofrecía información clara sobre las mesas y colegios electorales. La campaña electoral se centró en la organización de mítines en diversos lugares de la ciudad $^{31}$.

En otras provincias, la participación electoral católica adoptó formas distintas al movimiento de las ligas, bien porque éstas no pudieron organizarse, bien porque existía ya un candidato confesional -católico independiente, integrista o carlista-, que gozaba por sí solo de suficiente arraigo o apoyo como para no necesitar que se crease una plataforma electoral conjunta. Así ocurrió en Guipúzcoa en los distritos de San Sebastián y Zumaya con los católicos independientes Joaquín Arteaga y Rafael Picavea, director del diario El Pueblo Vasco, y en los distritos de Azpeitia y Tolosa, controlados por integristas y carlistas $^{32}$. Otro ejemplo es el del distrito electoral de Salamanca, donde el panorama político cuenta también con una destacada presencia de fuerte impronta católica, tradicionalista e integrista. Estos últimos, con notable influencia en la capital, tendrán su representación en el candidato Juan Antonio Sánchez del Campo, que ya había sido diputado por el distrito en $1901^{33}$. Mayor complejidad presenta el caso de Navarra, donde sí existían Ligas católicas, pero la profunda división entre las distintas fuerzas confesionales impidió la convergencia electoral. En los comicios de 1901, 1903 y 1905, integristas y carlistas no lograron un acuerdo ${ }^{34}$; los primeros pactaron apoyo recíproco en la circunscripción con el jefe del partido conservador, el marqués de Vadillo ${ }^{35}$,

31. Aguiló Lucía, Luís, Sociología electoral valenciana (1903-1923). Las elecciones en Valencia durante el reinado de Alfonso XIII, Valencia, 1976, p. 82.

32. Cillán Apalategui, Antonio, Sociología electoral de Guipúzcoa, 1900-1936, San Sebastián, 1975.

33. Díez Cano, Santiago y Carasa Soto, Pedro «Caciques, Dinero y Favores. La Restauración en Salamanca», en Historia de Salamanca, Vol. V, Siglo XX, Salamanca, 2001, pp. 87-198, esp. pp. 122 y 123. Sin embargo, en 1901 Sánchez del Campo contó con el apoyo de un conjunto de fuerzas católicas que dejaron al margen sus disputas para arropar al candidato católico integrista con la aprobación de los jesuitas. Cfr. REvUELTA GONZALEZ, Manuel, op. cit., p. 763, nota 325.

34. Véase Robles Muñoz, Cristóbal, art. cit., y Urabayen Minura, Juan P. «Católicos navarros y anticlericalismo, Elecciones Generales de 1901», en Congreso de Historia de Euskal Herria, II Congreso Mundial Vasco, San Sebastián, 1988, VI, pp. 345-361.

35. En 1903 Maura insistía al gobernador civil de Navarra que Nocedal debía ser elegido por Pamplona, pues era «de interés político para el gobierno que no falte la representación del jefe integrista». Citado por MinA, María Cruz, «Elecciones y partidos políticos en Navarra (1891-1923)», en La España de la Restauración, política, economía, legislación y cultura, Madrid, 1985, pp. 119-129, esp. p. 117. 
al tiempo que los segundos avanzan en la representación electoral en solitario, sumando tres diputados en 1901 y 1905, y cuatro en 1903.

Sin embargo, independientemente de la presentación de candidatos propios o del apoyo a candidatos afines, los católicos aprovecharon las elecciones de 1903 y de 1905 para intensificar su propaganda. En este contexto se publicaron diversos folletos que darán base teórica al discurso propagandístico católico, justificando la concurrencia electoral. Independientemente de que, al final, se optase por la abstención, por no ser factible una candidatura que recibiese el respaldo católico, las indicaciones de las jerarquías eclesiásticas y la propaganda de los teóricos católicos, en especial del Apostolado de la Prensa, se presentan siempre con una visión de futuro, de cara a ir articulando la unión y completando la organización electoral de los católicos para próximas convocatorias.

Con las elecciones de 1905, los católicos tendrán una nueva oportunidad para fortalecer su organización e intensificar su movilización, alentada ahora por corresponder la convocatoria al turno liberal. La presencia electoral católica fue menos significativa de lo esperado, salvo en las ciudades donde concurrieron las Ligas. Éste fue el caso de los católicos valencianos, que diseñaron una moderna campaña que discurrió entre las reuniones electorales en los barrios y distritos de la ciudad y la organización de actos de presentación de candidatos y mítines, en los que se criticaba el programa anticlerical que pretendían llevar a cabo los liberales en el gobierno nacional y los republicanos en el local ${ }^{36}$. Sin embargo, el balance general de la participación electoral de los católicos no fue positivo por el recrudecimiento de las disensiones internas y políticas en sus filas, como ocurrió en las Ligas de Sevilla y Navarra. La imagen de desunión restó impulso a la movilización política, propiciando el retraimiento, la abstención o el desplazamiento del voto católico a los conservadores. Estas circunstancias aconsejaron que se replantease de nuevo la unidad de los católicos ante las elecciones, como reflejan las pastorales del cardenal Casañas, obispo de Barcelona y del cardenal Sancha, arzobispo de Toledo que, con motivo de las elecciones municipales de noviembre de 1905, condenaban el retraimiento de los católicos llamando a la superación del partidismo político en la lucha electoral ${ }^{37}$.

36. La Voz de Valencia, 1, 2, 4 y 5 de septiembre de 1905.

37. Boletín Oficial Eclesiástico del Obispado de Barcelona, 24-10-1905 y «Consejos al clero y católicos», en Boletín Eclesiástico del Arzobispado de Toledo, 16-10-1905. 


\section{Las elecciones de 1907. Del «mal menor» al fantasma del anticlericalismo: la Ley de Asociaciones}

Unos resultados electorales menos positivos de lo esperado en las elecciones de 1903 y 1905 volvieron a demostrar que la impotencia católica en la lucha electoral que se debía básicamente a las desavenencias internas y al rechazo de integristas y carlistas a perder protagonismo como principales fuerzas políticas confesionales. Esa falta de unidad electoral y política debilitaba considerablemente la capacidad de oposición de la opinión católica ante las eventuales «agresiones» laicistas. Para muchos sectores católicos, era necesario replantear la lucha electoral con una nueva estrategia que recomendaba, antes que la abstención, el voto a los candidatos «menos malos», lo que abría la posibilidad de votar al partido conservador frente a candidatos liberales, demócratas o republicanos.

Con la publicación en la revista Razón y Fe de la Compañía de Jesús de unos artículos que, firmados por los padres V. Minteguiaga y P. Villada, defendían sin ambages esta nueva orientación del voto católico, surgirá una gran controversia reflejo de la profunda división de los católicos españoles en materia electoral ${ }^{38}$. La llamada polémica del «mal menor» se centraba en tres aspectos fundamentales: el deber ineludible de los católicos de concurrir a las elecciones, la importancia de la unión y organización católica para este objetivo, y los criterios para escoger, en caso de que existiese competencia electoral, aquella candidatura que supusiera para la Iglesia el «mal menor», estableciendo una gradación entre los posibles candidatos. El rechazo integrista a esta doctrina, a través del periódico El Siglo Futuro ${ }^{39}$, provocó un intenso debate, que intentó zanjar Pío X con la carta Inter Catholicos Hispaniae, remitida en febrero de 1906 al obispo de Madrid, Victoriano Guisasola ${ }^{40}$. El documento pontificio, elaborado para evitar la confrontación entre católicos por discordias de partido, refrendaba el contenido básico de los artículos de Razón y Fe

38. Véase MinteguiagA, Vicente, «Algo sobre las elecciones municipales» y ViLLADA, Pablo, «De elecciones», Razón y Fe, XIII, Madrid, 1905, pp. 141-156 y 450-463, respectivamente.

39. El Siglo Futuro consideraba esta nueva estrategia como una traición de los jesuitas a las posturas condenatorias del liberalismo que habían defendido hasta entonces. La contestación de R. Nocedal, director de El Siglo Futuro, a los artículos de Razón y Fe, en Nocedal, Ramón, Obras completas, Tomo III, Artículos I-El Mal Menor, Imp. de Fortanet, Madrid, 1909, pp. 3-343.

40. Podemos encontrar un reciente resumen de la polémica en MARTínEz EsTEBAn, Andrés, Aceptar el poder constituido. Los católicos españoles y la Santa Sede en la Restauración (1890-1914), Madrid, 2006, pp. 358-380; y también, desde la perspectiva de la historia de los jesuitas, en RevUelta GonZalez, M., op. cit., pp. 763-777. 
respecto a la elección de los candidatos «que han de mirar mejor por los intereses de la religión y de la Patria en el ejercicio de su cargo público», e insistía en la necesidad de unidad y participación electoral de los católicos:

«Tengan todos presentes que, ante el peligro de la religión o del bien público, a nadie es lícito permanecer ocioso (...) Por lo tanto es menester que los católicos eviten con todo cuidado tal peligro, y así dejados a un lado los intereses de partido, trabajen con denuedo por la incolumidad de la religión y de la Patria...» $»^{41}$.

El pronunciamiento del Vaticano eclipsó de momento el debate, pero no completamente, pues las elecciones de 1907 hicieron que se reabriera la polémica de nuevo y con mayor virulencia, si cabe, en un contexto de movilización católica creciente frente a la legislación de apertura en materia religiosa del Gobierno liberal español de 1905-1906 que culminará, posteriormente, con la del Ejecutivo del demócrata José de Canalejass ${ }^{42}$. En un clima de mayor desencuentro entre el Estado y la Iglesia, el fantasma del anticlericalismo se encarnó en el proyecto de Ley de Asociaciones que era contemplado por las jerarquías eclesiásticas, en un claro paralelismo con el proceso de secularización francés $^{43}$, como un ataque en toda regla al sentir católico del pueblo español, y que suscitó una intensa reacción y movilización en contra. La formación del Gobierno conservador de Maura, que incluía ministros de clara significación católica como Cierva, Rodríguez San Pedro y el marqués de Figueroa, y la derogación de la Real Orden liberal de 1906 sobre el matrimonio civil ${ }^{44}$ contribuyeron a suavizar un poco la crispación, pero sin eliminarla plenamente ${ }^{45}$. El activismo católico se centró ahora en el proyecto de ley de Asociaciones:

41. «Carta Inter Católicos Hispaniae...», en De elecciones. Reglas de conducta para católicos, Imp. de la «Revista de Arch. Bibl. y Mus., 1906, p. 6. Este folleto recopila gran parte de la documentación sobre esta polémica. La perspectiva vaticana ante esta espinosa cuestión, en ASV, Nunziatura di Madrid, leg. 654.

42. Sobre la figura de Canalejas y su política en materia religiosa, véase FORNER MUÑOz, S., Canalejas y el Partido Liberal Democrático, Madrid, 1993.

43. Carta Pastoral de los Prelados de la provincia eclesiástica de Compostela al clero y fieles de la misma, Imp. del Seminario, Santiago, 1906; PÉREZ, Antonio, «La separación del Estado y de la Iglesia en Francia», Razón y Fe, XIV, Madrid, 1906, pp. 137-150; y R.M.V., «Las instrucciones pastorales de los obispos contra el anticlericalismo actual», Razón y Fe, XVI, Madrid, 1906, pp. 394-401.

44. Junto al proyecto de la Ley de Asociaciones, la R.O. sobre el matrimonio civil había sido el caballo de batalla de la propaganda y movilización católica. Véase MiNTEGUIAGA, Vicente, «La Real Orden Circular sobre matrimonios civiles», Razón y Fe, XV, Madrid, 1906, pp. 161-177

45. Andrés-Gallego habla de una «tácita compenetración» entre el Gobierno conservador y el Vaticano. ANDRÉS-GALLEGO, José, «Transformación política y actitud religiosa 
«La amenaza contra las Órdenes religiosas solivianta a los católicos españoles. La prensa católica da la voz de alarma, los pueblos se mueven; almas enfervorizadas en celo por la religión provocan reuniones, asambleas numerosas, mítines extraordinarios de protesta viva, enérgica, valiente... $\gg^{46}$.

La movilización culminó a finales de enero de 1907 en una exitosa manifestación católico-carlista contra el proyecto de ley que, en una ostentación de fuerza sin precedentes, congregó en Barcelona a unas 20.000 personas, recibiendo por este motivo la felicitación expresa de Pío X en una carta que, dirigida al Obispo de la diócesis, se convertirá, dada la proximidad de las elecciones, en un auténtico manifiesto electoral. ${ }^{47}$

Ante el anuncio de nuevas elecciones, las autoridades eclesiásticas y los católicos de base volvieron a volcarse en la organización y movilización electoral. El carácter modernizador de esa participación católica en 1907 proviene en gran parte de la confrontación en clave ideológica que impregna su campaña electoral frente al discurso anticlerical. El llamamiento en los diarios católicos a la unión y a la movilización se justifica en la llamada «defensa social» católica frente al enemigo liberal, demócrata y republicano ${ }^{48}$. De hecho, el activismo católico, la intervención de la Iglesia y la conveniencia del voto católico centraron la campaña electoral en algunos lugares de España, siendo destacados por la prensa política del momento como una de las principales señas de identidad de estas elecciones.

La propaganda y la beligerancia católica se exteriorizan no sólo en los actos electorales, sino que se expresan también en manifestaciones públicas de culto o celebraciones multitudinarias de rituales religiosos, a las que acompañaban conferencias y asambleas en los centros y asociaciones católicas e, incluso, reuniones en los domicilios particulares de ilustres personajes ${ }^{49}$. La labor propagandística del clero y las jerarquías desde el púlpito y a través de la difusión de determinados documentos pontificios o episcopales también fue decisiva: «A las elecciones vamos. Y vamos con nuestros Prelados y nuestros párrocos delante, enseñándonos y empujándonos a que luchemos... ${ }^{50}$.

del Gobierno largo de Maura (1907-1909)», en Revista de Estudios Políticos, 189-190 (1973), pp. 131-163, pp. 137-138 y 152.

46. La Lectura Dominical, Madrid, 15-12-1906, p. 788.

47. ASV, Nunziatura de Madrid, leg. 654, fasc. 1, fol. 208 y ss.

48. Diario de León, 1-3-1907. En la prensa católica, para justificar la necesidad de movilizarse, se afirma que la masonería había organizado en las logias plataformas electorales de apoyo a los candidatos de orientación anticlerical. Cfr. La Lectura Dominical, Madrid, 27-3-1907, p. 182.

49. La Lectura Dominical, Madrid, 8-12-1906, p. 773.

50. Ibíd., 30-3-1907, p. 196. 


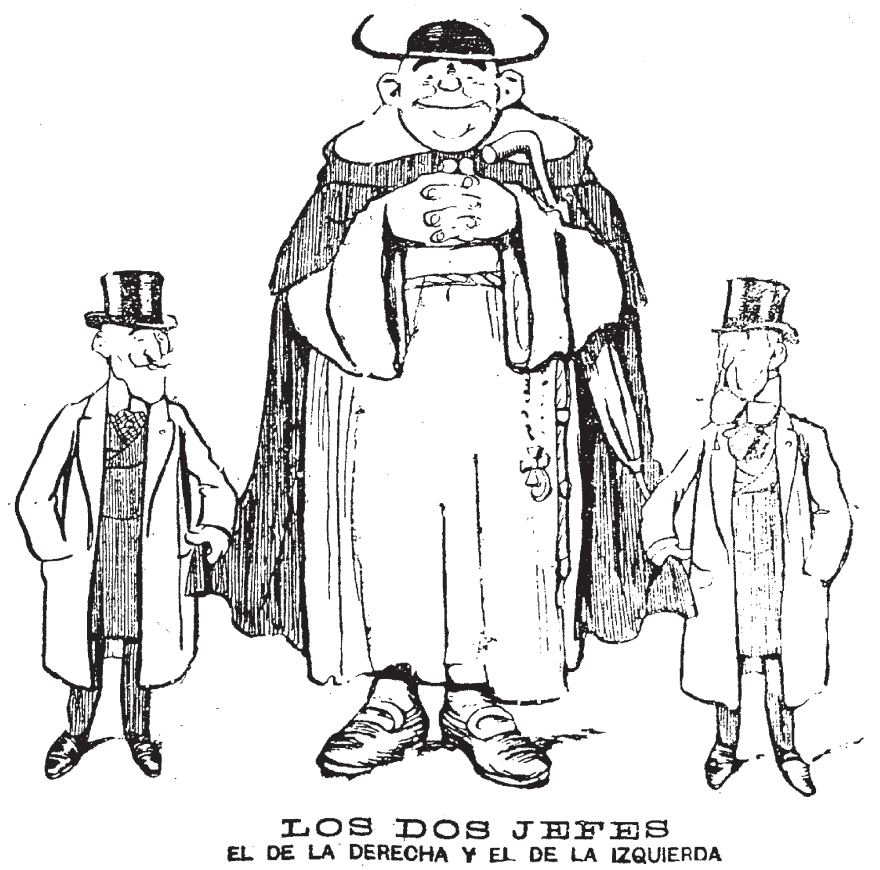

Fuente: Heraldo de Madrid, 24 de febrero de 1907

La Carta Pastoral del Obispo de Madrid-Alcalá sirvió de documento marco, al que siguieron otras «beligerantes» pastorales de varios obispos que, difundidas por la prensa católica en las semanas previas a las elecciones, abonaban el terreno para la movilización y, en especial, para una propaganda que, como primer paso, tenía por objeto propiciar la participación electoral de los católicos ${ }^{51}$. Tan numerosas fueron estas pastorales que la revista Razón y Fe se refería a ellas, recalcando que la nota especial de las Cartas e Instrucciones pastorales de Cuaresma había sido ese año la política-religiosa «oportunísima para guiar a los fieles en el cumplimiento de sus deberes de ciudadanos católicos para con la Iglesia y con la sociedad $»^{52}$. Un ejemplo de este tipo de pastorales «electorales» lo encontramos en la firmada por el Obispo de León:

«Es un hecho, del que no se puede dudar, que a pesar de ser España una nación católica y por consiguiente creyente en la mayoría de sus hijos, sin embargo la impiedad avanzó con pasos de gigante, los enemigos de Cristo

51. Los católicos y las elecciones, en Apostolado de la Prensa, n CLXXXIII, Madrid, 1907. 52. Razón y Fe, XVII, Madrid, 1907, p. 551. 
ganan terreno (...) Mostraos también fuertes en vuestra fe, interesándoos por el reinado de la Religión en nuestra amada España. Vosotros los que no ha mucho levantasteis vuestra voz de protesta contra el malhadado proyecto de asociaciones por considerarlo atentatorio a los derechos de Ntra. Santa Madre la Iglesia y contrario a los principios de nuestra fe, zusaréis el derecho de sufragio que la ley civil os concede, eligiendo para los cargos públicos a personas hostiles a la Iglesia misma o sospechosas en la fe, sin considerar la gravísima responsabilidad en la que habéis de incurrir? $\star^{53}$.

Pero el principal escollo para una respuesta de unidad electoral católica seguía siendo la división política interna. El Obispo de Madrid-Alcalá, como portavoz del episcopado español y recogiendo los dictados pontificios, insistía en varios párrafos de su pastoral del 20 de febrero en la unidad católica, dejando al margen los partidos o posiciones políticas:

«Para que sea más eficaz la acción electoral, han de luchar unidos todos los católicos, sin que se trate por nadie de que se disuelva un partido católico y se sume a un liberal o transija con los errores de éste (...) cuando se trata de defender los intereses de Dios y de su Iglesia, debe cada uno de vosotros prescindir generosamente de sus propias opiniones y unirse estrechamente a su Obispo para formar, sin distinciones de partidos, aquella unión de católicos que constituye la fuerza; la fuerza da después la victoria.... $»^{54}$.

Siguiendo las mismas directrices, los prelados españoles fijaron unas instrucciones básicas para guiar a los católicos ante la cita electoral, y las harán públicas en sus pastorales:

1. «Los ciudadanos tienen obligación en general de acudir a los comicios y elegir candidatos buenos e idóneos para procurar el verdadero progreso: el bien público de la religión y de la patria».

2. «Esta obligación de justicia legal o de caridad para con la sociedad es, por su naturaleza, grave; de modo que no habiendo causa excusante, puede pecar mortalmente quien se abstiene de votar cuando esa sea causa de que no sea elegido el candidato bueno o salga triunfante el hostil a la Iglesia».

3. «Cuando hay competencia entre un católico idóneo y un anticlerical o liberal en el sentido eclesiástico de la palabra, no es lícito por ninguna razón de amistad, agradecimiento, etc., votar al liberal contra el católico. Si la competencia fuese entre un católico idóneo y otro más idóneo también católico, convendrá dar el voto al más idóneo para lograr el mayor bien social $»^{55}$.

Poco después, para evitar la confrontación en las filas católicas, los obispos convinieron una fórmula electoral que presentaba a los candidatos más

53. Diario de León, 2, 4 y 5-3-1907

54. Razón y Fe, XVII, Madrid, 1907, pp.408-409.

55. Diario de León, 15-4-1907. 
idóneos, categoría en la que cabrían tanto los católicos genuinos, como afines, es decir los integristas o carlistas, pero siempre sujetos a una serie de requisitos mínimos y compromisos que deberían asumir si querían ser avalados por la Iglesia:

1. «A defender las prerrogativas de la Santa Madre Iglesia Católica, apostólica, romana, bajo la dirección del Prelado.

2. A combatir por todos los medios el proyecto de ley de Asociaciones.

3. A defender y apoyar la independencia económica de la Iglesia.

4. A sostener y defender la supremacía de la Iglesia, cualquiera sea el Gobierno que intentase atentar contra ella ${ }^{56}$.

Sin embargo, no en todos los distritos o circunscripciones había posibilidad de presentar candidatos católicos o, simplemente, éstos no eran avalados por el prelado de la diócesis. En este caso, las instrucciones también eran claras: se debía aplicar la doctrina del «mal menor», lo que, en la práctica, significaba respaldar a los candidatos conservadores ${ }^{57}$, postura que venía avalada por el destacado componente católico del gobierno Maura y por el mensaje que, sobre la defensa de la religión, era enarbolado igualmente por algunos políticos conservadores, especialmente en aquellos distritos donde competían contra republicanos o demócratas. Pero esta doctrina será también fuente de discordia y enfrentamiento entre diversos sectores católicos, jerarquías eclesiásticas y elites políticas, generando importantes conflictos en la elaboración del encasillado en varios distritos. Así pues, aunque la actitud general de los católicos en 1907 es de movilización activa, nos encontramos, por el fraccionamiento existente y como consecuencia de las propias instrucciones eclesiásticas, con una diversa tipología de casos que se materializan en el apoyo de las bases católicas a candidatos idóneos, afines o conservadores, dependiendo de las características y circunstancias propias del distrito o circunscripción electoral.

Para la designación del candidato idóneo o menos malo, la supervisión episcopal era fundamental e, incluso, en algunos lugares el protagonismo de los obispos fue enorme. En Salamanca, por ejemplo, con el objeto de preparar una candidatura católica se convocó una reunión bajo la presidencia del Obispo, que señaló al numeroso público asistente que, ante las elecciones, «el católico no puede permanecer inactivo, sino que debe de acudir a las urnas y votar a aquel candidato que estime más útil para los intereses de la Iglesia ${ }^{58}$.

56. Ibídem.

57. SoldeVilla, F, El año político de 1907, Madrid, p. 81, 94-95, 98-99, 103-104. Véase también, Los católicos y las elecciones, op. cit.

58. La Victoria, Semanario de Béjar, Salamanca, 23-3-1907. Hemos tratado de forma monográfica el caso de Salamanca, en «Las elecciones de 1907 en Salamanca: un ejemplo 
Sin embargo, pronto estalló la polémica al perfilarse como candidato Juan Lamamié de Clairac, director del periódico de orientación ultra-católica El Salmantino y al que avalaban Nocedal y Juan Antonio Sánchez del Campo, diputado integrista en 1901 y 1903 por el distrito de Salamanca. En este debate se evidenció la divergencia de posturas entre los católicos ante las elecciones: ¿Se debía respaldar a un candidato con un firme compromiso de defender la religión oponiéndose a todas aquellas medidas legislativas o gubernamentales que pusieran en peligro a la fe católica, pese a su militancia en el integrismo o carlismo? o, por el contrario ¿se debía apoyar sólo a los católicos independientes sometidos únicamente a la obediencia de los prelados? Algunos obispos y sacerdotes preferían dar su apoyo a un conservador antes que avalar a un carlista o integrista, ya que éstos se sometían a la disciplina de sus partidos antes que a la de la Iglesia. En esta postura también subyacen el deseo de la jerarquía de reforzar su autoridad, el temor a una movilización de las bases católicas que escapase a su control e, incluso, su propia implicación en el entramado de favores y clientelas que sustentaba el sistema de la Restauración. En esta línea, el Obispo de Salamanca Francisco Javier Valdés, siguiendo las orientaciones vaticanas sobre la doctrina del «mal menor» y la Carta Inter Católicos Hispaniae, manifestaba en una pastoral del 5 de abril su rechazo a Clairac por su condición de integrista y por su falta de sometimiento a la autoridad eclesiástica:

«Que no nos es posible recomendar como candidato católico llamado a defender sobre todo otro interés de partido o bandería, los intereses sagrados de la religión a ninguna persona que, aun gozando justa fama de creyente y piadoso, no empiece por reconocer la autoridad de su legítimo Prelado (...) en la situación actual de la política en nuestra ciudad, estimamos que entre los candidatos católicos, aquél que será más acreedor a la confianza de los electores católicos que a las condiciones señaladas en el número anterior, reúna mejores prendas personales de aptitud para las luchas de la política, y a ser posible, obtenga la protección oficial...»"

Resulta obvio que se inclinaba por el voto conservador ${ }^{60}$, una actitud que compartían los diarios El Adelanto y La Semana Católica. Éste último, órgano

de la movilización y confrontación electoral católica en la España de la Restauración», Studia Histórica. Historia Contemporánea, no 22 (2004), pp. 319-341

59. «De elecciones. El Obispo de Salamanca», 5-4-1907, en EL Lábaro, de la misma fecha. La cursiva es nuestra.

60. Así lo reconocía en una carta privada dirigida al ministro de la Gobernación el 26 de marzo: «...por ser convicción mía que (...) los derechos de la Iglesia y de la conciencia católica no tienen hoy en España más garantía de amparo y protección oficial que las que honradamente pueda dispensarle el partido conservador al que debieran por tanto 
del Centro Sacerdotal de Salamanca, en un artículo titulado «Actitud de los católicos», que firmaba su director, el sacerdote y reputado ensayista católico José Polo Benito, recomendó expresamente el voto al partido conservador frente a la opción carlista o integrista, haciendo gala de un claro pragmatismo político:

« ¿Y no sería beneficio nuestro la cooperación sincera, decidida y franca a favor del partido conservador, que es hoy el único representante oficial de las ideas católicas en las esferas gubernamentales? (...) Nosotros apoyaríamos a Maura en lo que tiene de católico, nuestro apoyo sería sencillamente una actitud (...) condicionada a los altísimos intereses de la fe, sería un oportunismo sano mensajero de ventajas nada despreciables ${ }^{61}$.

En los círculos políticos de Salamanca se sabía que era el obispo el que había inspirado el artículo, circunstancia que también se reconocía en la documentación privada que, sobre esta cuestión, el Nuncio Rinaldini remitió al Vaticano ${ }^{62}$. Al asumir parte de la prensa católica esa postura de apoyo a los conservadores, se reabrió de nuevo la controversia, que será protagonizada en esta ocasión por el Centro Sacerdotal de Salamanca y el diario integrista de Valladolid, El Porvenir ${ }^{63}$. Finalmente, dada la imposibilidad de encontrar un candidato conservador o católico idóneo, al obispo de Salamanca no le quedó más opción que apoyar a Clairac; eso sí, después de que éste declarara públicamente «reconocer y acatar, como siempre he reconocido y acatado, la sagrada autoridad que compete a los señores obispos en materias políticoreligiosas, y ante todo e inmediatamente al prelado de la propia diócesis ${ }^{64}$.

La presentación de candidaturas católicas independientes es cuantitativamente más reducida, pero significativa en determinadas provincias como en Vizcaya, Sevilla, León, Burgos o Alicante. En todos los casos, se trataba de contrarrestar el empuje de otros candidatos republicanos, liberales y demócratas

prestar decidido apoyo todos los católicos conscientes...», Archivo Cierva, Sec. A, leg. 37.

61. Recorte sin fecha en Archivo Maura, Leg. 60/14, carta de J. Maldonado a Maura, 303-1907. El artículo fue reproducido por la práctica totalidad de la prensa católica del momento.

62. ASV, Nunziatura de Madrid, leg. 654, fasc. 1. El diario El Universo reproducía el artículo y afirmaba que había sido autorizado por el obispo (5-4-1907), mientras que el tradicionalista El Correo Español lo negaba (4-4-1907).

63. Véase ¿Netos ó....? Datos para juzgar de cierta actitud política aconsejada a los católicos españoles y de una polémica sostenida por el Centro Sacerdotal de Salamanca, Salamanca, Imp. de Calatrava, 1908, y ¿Cuál es el bien mayor? Polémica sostenida con el Centro Sacerdotal de Salamanca en el diario de Castilla El Porvenir..., Valladolid, Imp. de Agapito Zapatero, 1907.

64. El Lábaro, Salamanca, 9-4-1907. 
que, por la debilidad de los conservadores o la permisividad gubernamental, tenían posibilidades reales de triunfar en los comicios.

En otras provincias, como Navarra y Logroño, los votos católicos se concentran sin discusión en candidatos carlistas o integristas, porque cuentan con más probabilidades de éxito que los católicos independientes. El partido carlista conseguirá en 1907 unos buenos resultados utilizando modernos medios de organización y propaganda, sumando un total de catorce diputados, la mayor representación de la Restauración. En Navarra, Vázquez de Mella y Nocedal, líderes tradicionalista e integrista respectivamente, constituyen a finales de marzo la «Alianza Católica Antiliberal», marginando a los conservadores, que sólo consiguieron pactar un escaño en la circunscripción para su jefe provincial, el marqués de Vadillo. En los cuatro distritos restantes de la provincia, los carlistas se imponen contando con el sólido y eficaz respaldo del clero. ${ }^{65}$

Un aspecto singular de la participación de los católicos en estas elecciones es su decido apoyo a la coalición electoral denominada de «Solidaridad Catalana», un movimiento de corte interclasista y de componentes muy diversos -catalanistas de la Lliga, carlistas y ciertos sectores republicanos- que se agrupaban en torno a la defensa de Cataluña frente a un férreo centralismo que frenaba sus aspiraciones autonomistas. Este movimiento canalizó el voto carlista y buena parte del católico frente a Lerroux, que lidera una plataforma política republicana y españolista ${ }^{66}$. Las candidaturas de la Solidaridad alcanzaron un gran éxito en las provincias catalanas, copando todos los escaños correspondientes a la de Barcelona. Y conviene remarcar que la Iglesia apoyó de forma mayoritaria estas candidaturas, puesto que el lerrouxismo, aunque de forma menos acentuada que en ocasiones anteriores, seguía presentando un discurso radical de tintes anticlericales. Sobre el respaldo eclesiástico a la Solidaridad, abundan los testimonios, comenzando por la propia documentación ministerial:

«...la Solidaridad Catalana que sumaba en su composición partidos retraídos hasta ahora de las luchas electorales y que por lo mismo han ido al combate con entusiasmo inexplicable dada la heterogeneidad de sus elementos, dándose el caso extraordinario de que los más ardientes de-

65. LaRraza, María Mar, Aprendiendo a ser ciudadanos. Retrato socio-político de Pamplona, 1890-1923, Pamplona, 1997, p. 121 y 160-163. Sobre los carlistas, CANAL, Jordi, El carlismo: Dos siglos de contrarrevolución en España, Madrid, 2000, p. 260.

66. BAlCElls, Albert; Culla, Joan B. y Mir, Conxita, Les eleccions a Catalunya de 1901 a 1923, Barcelona, 1982, p. 120. 
fensores de las candidatos republicanos solidarios fueron sus enemigos de siempre o sea los Carlistas, Integristas y Clero...» ${ }^{67}$.

Desde la prensa católica se intentaba justificar para el resto de España la actitud complaciente de la Iglesia ante la colaboración electoral de católicos y republicanos en Cataluña. Así lo hacía el P. Salvador Font en un artículo publicado en la revista agustiniana España y América:

«Han entrado en este movimiento, tomando en él parte activa, los prelados, los sacerdotes, los religiosos y los párrocos, que tienen en Cataluña inmensa influencia social. Las torpezas de los últimos gobiernos liberales levantaron de quicio al clero catalán y de las provincias del Norte, y fomentaron el bizcaitanismo y el catalanismo ${ }^{68}$.

Pese a este amplio respaldo católico a la coalición electoral catalana, también se alzaron voces críticas entre los sectores más reaccionarios de la Iglesia. Aunque minoritarios, manifestaron públicamente y al Vaticano su postura contraria:

«iQué monstruosidad! Cuando el despertar de los católicos, por tanto tiempo dormidos; cuando el despertar de los católicos fue al grito de ¡Abajo las órdenes religiosas! lanzado por los republicanos (...) tenga por resultado postrimero el unirse con esos mismos republicanos para que siga la fe blasfemada, buscando a la sombra de estas blasfemias la autonomía de Cataluña...! ${ }^{69}$.

\section{Una nueva ofensiva católica en las elecciones de 1910: la campaña contra las escuelas laicas}

La «cruzada» electoral católica no concluyó tras la contienda electoral de 1907, sino que tendría continuación en los años siguientes. La Semana Trágica y las elecciones de 1910 impulsarán de nuevo la beligerancia de los católicos, que cuentan ya con una sólida infraestructura periodística y asociativa, y con una asentada tradición de movilización. Tras la caída de Maura, se abría un nuevo turno liberal en el que se sucedieron varios gobiernos que intentaron poner en marcha medidas liberalizadoras en materia religiosa, provocando una auténtica colisión con el Vaticano ${ }^{70}$. La reacción de la Iglesia no se hizo esperar y Pío X, a la vista de las conclusiones negativas respecto a la Unión política y electoral a las que había llegado en 1908 la encuesta del Nuncio An-

67. Archivo Cierva, Sec. F, leg. 102. Memoria electoral de Lérida, 1907.

68. España y América, Año V, Tomo II, p. 107.

69. La voz del pontífice supremo y La Solidaridad Catalana, Lérida, 5-4-1907, en ASV, Nunziatura de Madrid, leg. 654, fasc. 1, fols. 169-170.

70. Ibídem, leg. 687, fasc.2, ff. 88-107. 
tonio Vico ${ }^{71}$, decidió encargar al nuevo Primado de Toledo, cardenal Aguirre, la reactivación de la acción católica y social, que contemplaba también una dimensión política. El encargo cristalizó en una reglamentación que, con el nombre de Normas de Acción Católica y Social en España, estructuraba y organizaba de forma definitiva el activismo católico. En relación con la unión político-electoral de los católicos, las Normas no introducían modificación alguna en las directrices marcadas anteriormente por el pontificado y el episcopado español, ya que consideraban correcto apoyar candidaturas no propias, en el supuesto de que se consideraran las menos malas para los objetivos de la Iglesia ${ }^{72}$.

La llegada al poder de los liberales desató una campaña de movilización sin precedentes que se alargó hasta la nueva convocatoria electoral. La prensa católica independiente y alguno de los principales teóricos católicos, marcando distancias con los integristas y carlistas, apostaban por la inserción plena de los católicos en la vida social y en la actividad pública y política ${ }^{73}$. En el discurso de destacados sectores católicos ya no se percibían, como antaño, críticas soterradas a las prácticas propias del sistema político liberal, sino que, al contrario, algunos escribían sobre la conveniencia del «catolicismo liberal». Se defiende de forma expresa la licitud del activismo político y electoral, y la libertad del voto como principios básicos de la ciudadanía política, a la que no podían, ni debían, renunciar los católicos para defender sus creencias y reivindicaciones:

«Ni valen las excusas antiguamente alegadas por algunos de que el caciquismo reinante y la desaprensión de muchos muñidores de elecciones es inútil dar el voto, que será fácilmente escamoteado. La nueva ley electoral (...) tiene de bueno que en el régimen actual favorece singularmente la libertad y sinceridad del sufragio (...) Acudamos, pues, a los comicios, a éstas y a todas las elecciones públicas cuantos no tengamos excusa verdadera; que si así lo hiciésemos (...) todavía podemos impedir el avance de la revolución...» ${ }^{74}$.

71. De la encuesta e informes del Nuncio Vico existe una amplia e interesante documentación en los archivos vaticanos. Véase ASV, Nunziatura di Madrid, leg. 679, fasc.1; Archivio della Sacra Congregazione degli Affari Ecclesiatici Straordinari (Vaticano), Spagna, 1908, Pos. 1039-1043, fasc. 411 y Pos. 1050-1054, fasc. 413.

72. La documentación vaticana sobre las instrucciones al Cardenal Aguirre y las normas en ASV, Segretaria di Stato, A. 1910, Rúb. 249, fasc. 9, ff. 6-11. Véase Normas de la Acción Católica y Social en España, 1910, Imp. Religiosa del Boletín Eclesiástico, Toledo.

73. Paláu, Gabriel, El Católico de acción, G.L. Horno, Madrid, 1906 (2ª ed.). Hubo varias reediciones posteriores (la $5^{a}$ se publicó en 1934).

74. Villada, Pablo, «La obligación del voto en la nueva ley electoral», Razón y Fe, XXIV, Madrid, 1909, pp. 58-66, esp. p. 65-66. 
La reapertura en febrero de 1910 de las escuelas laicas, clausuradas el año anterior por Maura, fue el revulsivo para otra gran ofensiva católica contra el proyecto de la Ley de Asociaciones de Canalejas y en defensa de la exclusividad católica en la enseñanza, que se trasladó de inmediato a un escenario político marcado por una gran confrontación electoral:

«Rara vez o nunca se ha notado en España, no tratándose de Cortes Constituyentes, tanta agitación electoral como la que estamos presenciando... y la prensa toda ha reconocido y proclamado la trascendencia excepcional de las próximas elecciones de este mes de Mayo. Es que se celebran en tiempos verdaderamente críticos para la nación (...) con orientaciones peligrosas por los compromisos anticlericales del jefe del Gobierno (...) enardecidos los ánimos con los fogosos discursos de oradores elocuentes en los mítines y manifestaciones públicas de tendencia diametralmente opuesta, antirreligiosa y católica, revolucionaria y tradicional, monárquica y republicana, que acaban de tenerse en todas las regiones; no parecerá extraño que cuando siguen con atención el curso de los acontecimientos públicos y observan la fuerza y fervor de los católicos, por un lado y, por otro la audacia y el fanatismo intolerante de los radicales y librepensadores, piensen que de estas elecciones puede salir o la ruina de la patria o su mayor esplendor» ${ }^{75}$.

Durante las elecciones de 1910, la utilización de modernos medios de propaganda electoral por parte de los católicos es notable. El mitin y la manifestación se van a convertir en los verdaderos protagonistas, ensayando la fórmula con entusiasmo en Madrid, Zaragoza, Barcelona, Salamanca, Sevilla, Castellón y Valencia. Esta activa movilización propagandística comienza meses antes de las elecciones, en una especie de precampaña que, alentada por los pronunciamientos individuales y colectivos del episcopado español ${ }^{76}$, desembocará en la organización de numerosos mítines por toda la geografía peninsular en protesta contra las escuelas laicas ${ }^{77}$.

Además de los actos electorales en sentido estricto, las procesiones y otras manifestaciones de culto litúrgico se convirtieron en actos de ostentación pública y política, ya que constituían elementos de singular importancia para la cohesión y la tradición cultural de las bases católicas, que en estos momen-

75. VilladA, Pablo, «Las elecciones legislativas de 1910», Razón y Fe, XXVII, 1910, Madrid, pp. $75-80$, p. 75.

76. Véase «Exposición que los reverendísimos Prelados de España han dirigido al Excmo. Sr. Presidente del Consejo de Ministros, contra la existencia de las escuelas llamadas laicas», 29-11-1909, reproducida en La Paz Social, III, 1909, pp. 601-604.

77. Un ejemplo son los mítines organizados en diversas localidades valencianas durante el mes de marzo de 1910, que son puntualmente reseñados por el diario católico La Voz de Valencia. 


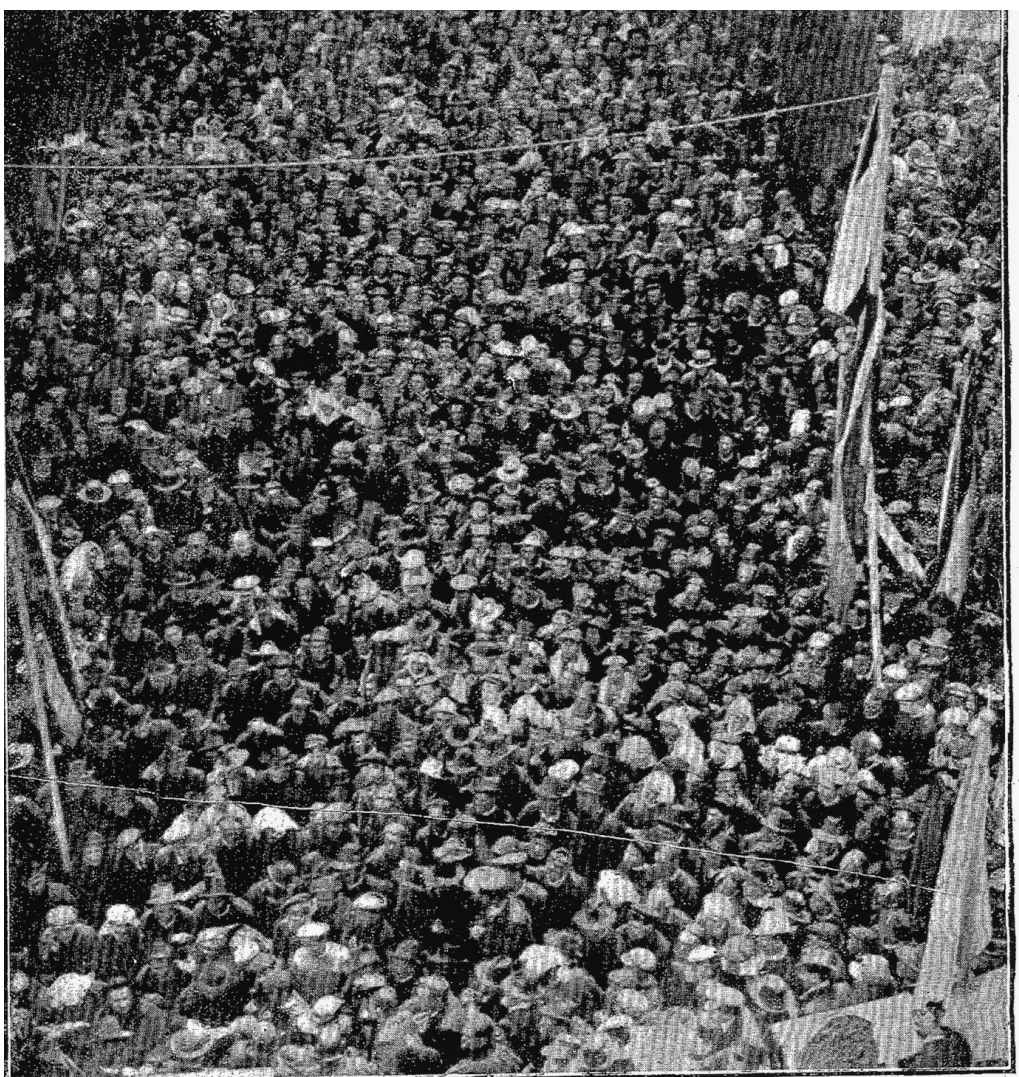

La CAMPAÑ CONTRA LAS ESCUELAS laICAS

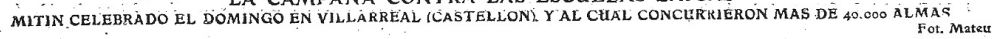

Fuente: ABC, 20 de abril de 1910.

tos interesaba popularizar con fines de movilización ${ }^{78}$. En todos estos actos, destaca una cierta unión entre los diversos sectores católicos, y en los mítines compartían la tribuna oradores católicos independientes e integristas, seglares y clérigos. De especial interés es la actuación del clero como difusor de la propaganda electoral y agente activo en la movilización político-electoral católica: «Ningún católico podrá ver con malos ojos que los eclesiásticos de-

78. Véase el interesante análisis de la funcionalidad de determinadas devociones y ritos litúrgicos en la movilización de los católicos en Cueva Merino, J. de la, «Clericalismo y movilización católica durante la Restauración», en Clericalismo y asociacionismo católico..., op. cit, pp. 27-50, esp. p. 40 y ss. 
fiendan el catolicismo y trabajen por el bien de la Iglesia, donde la defensa es más eficaz y el bien puede ser mayor, en el terreno de las elecciones administrativas y políticas» ${ }^{79}$.

Protagonismo inusitado adquirieron también las mujeres en esta campaña. La posible utilidad de las mujeres en las elecciones ejerciendo un auténtico apostolado sobre el sufragio masculino ya había sido defendida en $1903^{80}$ $y$, unos años antes, habían participado activamente en las primeras protestas en respuesta a las movilizaciones anticlericales con motivo del estreno de la obra Electra de Galdós ${ }^{81}$. En los años siguientes, la tradicional concepción católica de la mujer como trasmisora de la espiritualidad y valores cristianos a la familia en el espacio privado del hogar se fue modificando gracias a una creciente proyección en la esfera pública de la mujer seglar a través de la acción del apostolado, la beneficencia y la caridad, pero en la práctica su papel en el campo político siguió siendo insignificante. A partir de 1905, esto comienza a cambiar gracias a la cada vez mayor presencia femenina en la movilización católica y, desde 1909, la participación de las asociaciones católicas de mujeres en la campaña contra las escuelas laicas va a ser muy destacada. Especialmente motivadas en esta ocasión por haberse centrado el campo de batalla en la cuestión de la educación, un área que les había sido reservada por la Iglesia, se convirtieron en auténticos agentes electorales. Así ocurre, como comentaba un diario católico local, en Villarreal, en la provincia de Castellón, donde las mujeres, «sobreponiéndose a la debilidad de su sexo», organizaron y participaron como oradoras en un mitin electoral ${ }^{82}$. Las mujeres se incorporaban de pleno derecho al movimiento católico iniciando el proceso que les llevará años después, con la creación de la Acción Católica de la Mujer, a un activismo combativo y, en muchos casos, al compromiso en la reivindicación de sus derechos políticos. ${ }^{83}$

79. López Peláez, Antolín, El clero en la política, Gustavo Pili Ed., Barcelona, 1910, p. 201. Véase también PALÁU, Gabriel, La acción social del sacerdote: un campo de acción, Gustavo Gili Ed., Barcelona, 1907.

80. Gran Apostolado de las Señoras..., op cit.

81. Especialmente activas fueron las Señoras Católicas de Valencia que elevaron una nota de protesta y la presentaron a la Reina. Cfr. Boletín Eclesiástico del Arzobispado de Burgos, 20-6-1901.

82. La Cruz de Castellón, 16-4-1910.

83. Véanse los interesantes trabajos de I. BLASCO, en especial Paradojas de la ortodoxia. Política de masas y militancia católica femenina en España (1919-1939), Zaragoza, 2003. 